\title{
(6) OPEN ACCESS \\ Time trends in musculoskeletal disorders attributed to work exposures in Ontario using three independent data sources, 2004-2011
}

\author{
Cameron A Mustard, ${ }^{1,2}$ Andrea Chambers, ${ }^{1}$ Selahadin Ibrahim, ${ }^{1}$ Jacob Etches, ${ }^{1}$ \\ Peter Smith 1,2,3
}

${ }^{1}$ Institute for Work \& Health, Toronto, Ontario, Canada ${ }^{2}$ Dalla Lana School of Public Health, University of Toronto, Toronto, Ontario, Canada ${ }^{3}$ School of Public Health and Preventive Medicine, Monash University, Melbourne, Victoria, Australia

\section{Correspondence to} Dr Cameron Mustard, Institute for Work \& Health, 481 University Ave, Suite 800 Toronto, Ontario, Canada M5G2E9;

cmustard@iwh.on.ca

Received 8 July 2014 Revised 12 September 2014 Accepted 27 September 2014 Published Online First 13 October 2014

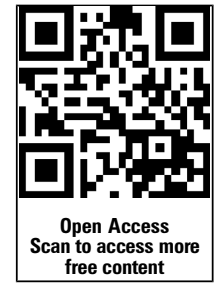

\section{SLinked}

- http://dx.doi.org/10.1136/ oemed-2014-102639

\section{CrossMark}

\section{To cite: Mustard CA,}

Chambers A, Ibrahim $S$,

et al. Occup Environ Med 2015;72:252-257.
ABSTRACT

Objective Work-related musculoskeletal disorders (MSDs) are the leading cause of work disability in the developed economies. The objective of this study was to describe trends in the incidence of MSDs attributed to work exposures in Ontario over the period 2004-2011.

Methods An observational study of work-related morbidity obtained from three independent sources for a complete population of approximately six million occupationally active adults aged 15-64 in the largest Canadian province. We implemented a conceptually concordant case definition for work-related non-traumatic MSDs in three population-based data sources: emergency department encounter records, lost-time workers' compensation claims and representative samples of Ontario workers participating in consecutive waves of a national health interview survey.

Results Over the 8-year observation period, the annual per cent change (APC) in the incidence of work-related MSDs was $-3.4 \%(95 \% \mathrm{Cl}-4.9 \%$ to $-1.9 \%)$ in emergency departments' administrative records, $-7.2 \%$ $(-8.5 \%$ to $-5.8 \%)$ in lost-time workers' compensation claims and $-5.3 \%(-7.2 \%$ to $-3.5 \%)$ among participants in the national health interview survey. Corresponding APC measures for all other work-related conditions were $-5.4 \%(-6.6 \%$ to $-4.2 \%),-6.0 \%$ $(-6.7 \%$ to $-5.3 \%)$ and $-5.3 \%(-7.8 \%$ to $-2.8 \%)$, respectively. Incidence rate declines were substantial in the economic recession following the 2008 global financial crisis.

Conclusions The three independent population-based data sources used in this study documented an important reduction in the incidence of work-related morbidity attributed to non-traumatic MSDs. The results of this study are consistent with an interpretation that the burden of non-traumatic MSDs arising from work exposures is declining among working-age adults.

\section{INTRODUCTION}

Musculoskeletal disorders (MSDs) are the dominant cause of disability burden among occupationally active adults. ${ }^{1}$ In the developed economies, nontraumatic MSDs incur direct and indirect economic costs of approximately $\$ 500$ million per million workers. ${ }^{2}$ While the aetiology of these disorders is complex, the role of physical and psychosocial work exposures in the initiation and progression of nontraumatic MSDs is well established. ${ }^{3-9}$ On the strength of this aetiological evidence, some

\section{What this paper adds}

- Musculoskeletal disorders are the dominant cause of disability burden among working adults in the developed economies, responsible for direct and indirect economic costs of approximately $\$ 500$ million per million workers.

- Over the past decade, the surveillance of workrelated musculoskeletal disorders has been intermittent.

- Using three independent population-based data sources, this study has described substantial declines in the incidence of work-related musculoskeletal disorders over an 8-year period in the province of Ontario.

- The results of this study are consistent with an interpretation that the burden of non-traumatic musculoskeletal disorders arising from work exposures is declining among working-age adults.

jurisdictions have introduced regulatory standards over the past two decades to control adverse biomechanical exposures at work. ${ }^{10} 11$

Research evidence concerning the effectiveness of workplace practices to identify and control adverse biomechanical exposures is mixed, with a number of recent systematic reviews calling for more rigorous research designs to improve evidence of effective practices to control hazardous exposures. ${ }^{12-14}$ Also poorly understood is the degree to which the introduction of new workplace equipment and technologies over the past decade has resulted in a net decrease or net increase in occupational exposures to adverse biomechanical demands. ${ }^{15} 16$

Against this backdrop, there have been periodic surveillance reports over the past decade documenting a declining incidence of work-related nontraumatic MSDs. Although there are differences in definitions used in these surveillance reports, a typical case definition describes MSDs as "cases where the nature of injury or illness is sprains, strains, tears; back pain, hurt back; soreness, pain hurt except the back, carpal tunnel syndrome, or musculoskeletal system and connective tissue disorders, when the event or exposure leading to the injury or illness is bodily reaction/bending, climbing, crawling, reaching, twisting; overexertion; or repetition". ${ }^{17}$ Surveillance reports have been based on administrative data sources maintained by work 
disability insurance schemes and labour protection authorities, ${ }^{2}{ }^{17-24}$ registries, ${ }^{2}$ self-reported morbidity obtained from representative survey samples ${ }^{25} 26$ and clinical occupational health surveillance. ${ }^{25} 27$ These reports generally document declining incidence trends in work-related musculoskeletal morbidity across a range of country settings, including Australia, the USA, the Netherlands and the UK. To date, surveillance of the incidence of work-related MSDs has not been reported for the period of economic recession following the 2008 global financial crisis, when hours of work declined sharply in the developed economies. ${ }^{28}$

The objective of this study was to describe trends in the incidence of work-related conditions in Ontario over the period 2004-2011 for a complete population of occupationally active adults aged 15-64. The study has a specific interest in comparing the trend in the incidence of work-related non-traumatic MSDs to the trend in incidence of other work-related conditions (traumatic injury and occupational illness). Three population-based data sources were used in this study: (1) administrative records of work-related conditions presenting for care in hospital emergency departments in Ontario (all residents are eligible for coverage for medically necessary healthcare under the single-payer, publicly-administered health insurance scheme), (2) administrative records of workers' compensation claims filed with the Ontario Workplace Safety and Insurance Board (the single payer of workers' compensation benefits in this jurisdiction) and (3) representative samples of Ontario workers participating in five consecutive waves of a national health interview survey.

\section{METHODS}

Two administrative data sources were used in this study: a census of all records for work-related conditions presenting for medical care in hospital emergency departments in Ontario and a census of all lost-time workers' compensation claims filed with the Ontario Workplace Safety and Insurance Board. These two administrative sources were supplemented with estimates of work-related conditions obtained from a representative sample of respondents to repeated waves of a national health interview survey. Estimates of participants in the Ontario labour force, derived from the Ontario Workplace Safety and Insurance Board estimates of the insured labour force or from labour force surveys, were used to compute the annual incidence rates.

\section{Study design}

A descriptive study of work-related conditions, obtained from three independent sources, for a complete population of approximately 6000000 occupationally active adults aged 15-64 in the Canadian province of Ontario.

\section{Data sources}

Administrative records of emergency department visits

The National Ambulatory Care Reporting System (NACRS) was established by the Canadian Institute for Health Information in 1997, providing data on individual patient visits to facility-based ambulatory care services, primarily emergency departments in acute care hospitals. ${ }^{29}$ In July 2000, the province of Ontario mandated the reporting of all emergency department visits to NACRS. For the purposes of this study, we obtained extracts for 1047458 NACRS records reported in the province of Ontario over the period 2004-2011 that were classified as indicating the clinical determination of a work-related cause of the injury or illness presenting for emergency department treatment. ${ }^{30}$ In Ontario, healthcare costs for the treatment of work-related conditions are reimbursed by the Workplace Safety $\&$ Insurance Board (WSIB). Variables in extracted records included a series of up to 10 fields documenting the main problem and the external cause of injury, coded to ICD-10-CA. ${ }^{31}$

\section{Administrative records of workers' compensation claims}

In Ontario, a single publicly-administered insurance agency, the WSIB, administers wage replacement benefits and purchases healthcare services in circumstances of work-related disability. Administrative records maintained by the WSIB contain information describing registered employers and the course and outcome of individual compensation claims. Electronic records of compensation claims resulting in the payment of wage replacement benefits (referred to as lost-time claims in this study) contain information on the date and time of injury, the employer's economic sector and the gender, age and occupation of the injured worker. In these records, a national coding stand$\operatorname{ard}^{32}$ is used to classify information describing the event that caused the work-related condition and the nature of the condition. Over the period 2004-2011, there were approximately 275000 lost-time compensation claims.

\section{Health interview surveys}

The Canadian Community Health Survey (CCHS) is an ongoing series of cross-sectional health interview surveys administered approximately every 2 years by the national statistics agency. ${ }^{33}$ Using a multistaged, stratified sampling frame, the CCHS target population consists of household residents aged 12 and older who are living in private dwellings in all provinces and territories. The survey design features and core content have remained largely unchanged during the series of surveys starting in 2001. For the purpose of the current analyses, respondents 15 years or older who had worked in the previous 12 months were included.

The study methods were reviewed and approved by the Research Ethics Board of the University of Toronto.

\section{Measures}

Work-related MSDs

We implemented a conceptually concordant case definition for work-related non-traumatic MSDs in each of the two administrative data sources. The case definitions required that the nature of the injury involved the musculoskeletal system and that the cause of injury excluded documentation of a traumatic cause. The implementation of the case definition in workers' compensation claims adopted standards established in Ontario to inform the development of a workplace MSDs prevention guideline. ${ }^{34} 35$ The eligible 'nature of injury' codes and 'injury event' codes are provided in online supplementary appendix table 2. In the emergency department data, the case definition for records with an eligible ICD-10-CA diagnostic code in the Injury classification family (S00-T99) required the absence of an accompanying ICD-10-CA code for a traumatic 'external cause' of injury (see online supplementary appendix 1). 'External cause' of injury coding is not applicable for records with an ICD-10-CA diagnostic code in the Musculoskeletal System classification family (M00-99). Eligible diagnostic codes in the Musculoskeletal System classification are listed in online supplementary appendix 1 .

Workers' compensation claim records and emergency department records that did not meet the case definition for workrelated MSDs were classified to a common category named 'other work-related conditions'. 
Work-related repetitive strain injury (self-reported)

Respondents to the CCHS health interview survey were provided information that repetitive strain injury is "caused by overuse or by repeating the same movement frequently (for example, carpal tunnel syndrome, tennis elbow, or tendonitis)". ${ }^{33}$ Respondents were asked whether they had any injuries due to repetitive strain which was serious enough to limit their normal activities in the past 12 months. Respondents who reported a repetitive strain injury were asked to identify the activity to which they attributed the cause of the injury, where response categories included "working at a job or business (excluding traveling to and from work)". We operationalised work-related repetitive strain injury as respondents who reported having a repetitive strain injury in the past 12 months which was respondent-attributed to exposures arising from working at a job or business.

\section{Work-related traumatic injury (self-reported)}

CCHS respondents were asked if they experienced an injury in the previous 12 months serious enough to limit their normal activities. ${ }^{36}$ Respondents reporting an activity-limiting traumatic injury were asked if that injury occurred in the course of employment and whether they had received medical attention by a health professional for the treatment of the injury within $48 \mathrm{~h}$ of the occurrence of the injury. In this report, we have estimated the incidence of work-related traumatic injury that required medical attention. This definition is conceptually concordant with regulatory criteria concerning the reporting of work-related injury or illness to provincial workers' compensation agencies.

\section{Labour force participants}

We relied on two separate sources of information to obtain annual denominators of labour force participants. For workers' compensation claims, we estimated the insured labour force eligible for coverage by the Ontario WSIB. Approximately 30\% of the Ontario labour force are in employment relationships that are excluded from coverage by the WSIB. ${ }^{37}$ For emergency department visit records, we used information from the Labour Force Survey to estimate the numbers of employed workers.

\section{Analysis}

The frequency distribution of records was tabulated for data obtained from workers' compensation records and from emergency department records. In producing rates and their CIs from the CCHS, survey weights were applied to adjust for probability of selection and non-response and bootstrap weights were used to account for the complexity of the sampling design. Incidence rates were calculated by dividing morbidity counts by the number of insured or employed workers. To estimate the annual per cent change (APC), rates were rescaled by dividing each rate in the time series by the rate at year 1 and then multiplying that value by 100 . The slope estimate and $95 \%$ CIs of the resulting linear regression model were used to estimate the APC.

\section{RESULTS}

Over the 8-year period 2004-2011, the number of employed persons in Ontario increased by $5.1 \%$ (table 1) and the estimated labour force insured by the WSIB increased by $1.9 \%$ (table 2). In the treatment of work-related conditions in Ontario emergency departments, the incidence of non-traumatic MSDs declined by $16.3 \%$ over the 8 -year observation period. The APC was $3.4 \%$ (95\% CI $-4.9 \%$ to $-1.9 \%$; table 1$)$. The incidence of other work-related conditions declined by $30.2 \%$ over the 8 -year observation period (APC: $-5.4 \%, 95 \%$ CI $-6.6 \%$ to $-4.2 \%)$. The per cent of all emergency department visits for work-related conditions that were due to non-traumatic MSDs increased from $20 \%$ to $23 \%$ over this period.

Among accepted lost-time claims in the provincial workers' compensation insurance scheme, the incidence of non-traumatic MSD conditions declined by $48.2 \%$ over the 8 -year observation period (APC: $-7.2 \%, 95 \%$ CI $-8.5 \%$ to $-5.8 \%$; table 2 ). The incidence of other work-related conditions declined by $39.4 \%$ (APC: $-6.0 \%, 95 \%$ CI $-6.7 \%$ to $-5.3 \%$ ). The per cent of all lost-time compensation claims that were due to non-traumatic MSDs was stable over the period 2004-2009 and then decreased from $45 \%$ (2009) to 40\% (2011).

From the national health interview surveys, the self-reported incidence of work-related repetitive strain injury declined by $41.7 \%$ over the 9-year period 2001-2010 (APC: $-5.3 \%, 95 \%$ CI $-7.2 \%$ to $-3.5 \%$; table 3 ). Over this same period, the incidence of work-related traumatic injury declined by $45.1 \%$

Table 1 Annual incidence of ED visits for work-related conditions, 2004-2011 occupationally active adults aged 15-64, Ontario, Canada

\begin{tabular}{|c|c|c|c|c|c|c|c|c|}
\hline \multirow[b]{2}{*}{ Year } & \multirow[b]{2}{*}{$\begin{array}{l}\text { Employed } \\
\text { persons }\end{array}$} & \multicolumn{2}{|c|}{ Non-traumatic MSD conditions } & \multicolumn{2}{|c|}{ Other work-related conditions } & \multicolumn{2}{|c|}{ All work-related conditions } & \multirow[b]{2}{*}{$\begin{array}{l}\text { Ratio: MSD } \\
\text { rate total rate }\end{array}$} \\
\hline & & $\begin{array}{l}\text { ED } \\
\text { visits }\end{array}$ & $\begin{array}{l}\text { Rate per } 1000 \\
\text { employed persons }\end{array}$ & $\begin{array}{l}\text { ED } \\
\text { visits }\end{array}$ & $\begin{array}{l}\text { Rate per } 1000 \\
\text { employed persons }\end{array}$ & $\begin{array}{l}\text { ED } \\
\text { visits }\end{array}$ & $\begin{array}{l}\text { Rate per } 1000 \\
\text { employed persons }\end{array}$ & \\
\hline 2004 & 6185900 & 31817 & 5.14 & 131344 & 21.23 & 163161 & 26.38 & 0.20 \\
\hline 2005 & 6241600 & 33344 & 5.34 & 133940 & 21.46 & 167284 & 26.80 & 0.20 \\
\hline 2006 & 6320300 & 33761 & 5.34 & 122171 & 19.33 & 155932 & 24.67 & 0.22 \\
\hline 2007 & 6421400 & 33882 & 5.28 & 115631 & 18.01 & 149513 & 23.28 & 0.23 \\
\hline 2008 & 6492400 & 31888 & 4.91 & 109480 & 16.86 & 141368 & 21.77 & 0.23 \\
\hline 2009 & 6321700 & 26118 & 4.13 & 89700 & 14.19 & 115818 & 18.32 & 0.23 \\
\hline 2010 & 6408800 & 27966 & 4.36 & 93430 & 14.58 & 121396 & 18.94 & 0.23 \\
\hline 2011 & 6517100 & 28033 & 4.30 & 96543 & 14.81 & 124576 & 19.12 & 0.23 \\
\hline $\begin{array}{l}\text { Predicted slope of } \\
\text { rate }(95 \% \mathrm{Cl})^{*}\end{array}$ & & & $-0.18(-0.25$ to -0.10$)$ & & $-1.14(-1.40$ to -0.89$)$ & & $-1.32(-1.62$ to -1.02$)$ & \\
\hline $\begin{array}{l}\text { Annual per cent } \\
\text { change }(\%)(95 \% \mathrm{Cl})\end{array}$ & & & $-3.4(-4.9$ to -1.9$)$ & & $-5.4(-6.6$ to -4.2$)$ & & $-5.0(-6.1$ to -3.9$)$ & \\
\hline
\end{tabular}


Table 2 Annual incidence of lost-time compensation claims for work-related conditions, 2004-2011 full-time equivalent workers insured by the Workplace Safety \& Insurance Board, Ontario, Canada

\begin{tabular}{|c|c|c|c|c|c|c|c|c|}
\hline & \multirow[b]{2}{*}{$\begin{array}{l}\text { Insured full-time } \\
\text { equivalents }\end{array}$} & \multicolumn{2}{|c|}{ Non-traumatic MSD conditions } & \multicolumn{2}{|c|}{ Other work-related conditions } & \multicolumn{2}{|c|}{ All work-related conditions } & \multirow[b]{2}{*}{$\begin{array}{l}\text { Ratio: MSD } \\
\text { rate total rate }\end{array}$} \\
\hline & & $\begin{array}{l}\text { Lost-time } \\
\text { claims }\end{array}$ & $\begin{array}{l}\text { Rate per } 1000 \\
\text { full-time equivalents }\end{array}$ & $\begin{array}{l}\text { Lost-time } \\
\text { claims }\end{array}$ & $\begin{array}{l}\text { Rate per } 1000 \\
\text { full-time equivalents }\end{array}$ & $\begin{array}{l}\text { Lost-time } \\
\text { claims }\end{array}$ & $\begin{array}{l}\text { Rate per } \\
1000 \text { full-time } \\
\text { equivalents }\end{array}$ & \\
\hline 2004 & 4783118 & 42051 & 8.79 & 53015 & 11.08 & 95066 & 19.87 & 0.44 \\
\hline 2005 & 4803023 & 41731 & 8.69 & 52264 & 10.88 & 93955 & 19.56 & 0.44 \\
\hline 2006 & 4822903 & 39585 & 8.21 & 47565 & 9.86 & 87150 & 18.07 & 0.45 \\
\hline 2007 & 4861366 & 38458 & 7.91 & 46101 & 9.48 & 84559 & 17.39 & 0.45 \\
\hline 2008 & 4861822 & 36250 & 7.46 & 44524 & 9.16 & 80774 & 16.62 & 0.45 \\
\hline 2009 & 4733758 & 30128 & 6.36 & 36238 & 7.66 & 66366 & 14.02 & 0.45 \\
\hline 2010 & 4797541 & 25137 & 5.24 & 34743 & 7.24 & 58880 & 12.48 & 0.42 \\
\hline 2011 & 4874459 & 22167 & 4.55 & 32722 & 6.71 & 54889 & 11.26 & 0.40 \\
\hline $\begin{array}{l}\text { Predicted slope of } \\
\text { rate }(95 \% \mathrm{Cl})^{*}\end{array}$ & & & $-0.63(-0.75$ to -0.51$)$ & & $-0.66(-0.74$ to -0.59$)$ & & $-1.31(-1.49$ to - & .13) \\
\hline $\begin{array}{l}\text { Annual per cent } \\
\text { change }(\%)(95 \% \mathrm{Cl})\end{array}$ & & & $-7.2(-8.5$ to -5.8$)$ & & $-6.0(-6.7$ to -5.3$)$ & & $-6.6(-7.5$ to -5.7 & \\
\hline
\end{tabular}

(APC: $-5.3 \%, 95 \%$ CI $-7.8 \%$ to $-2.8 \%)$. The per cent of all work-related morbidity attributed to self-reported repetitive strain injury was in the range of $75 \%$.

In the economic recession following the global financial crisis, employment estimates declined in both denominator series (employed persons: 2008-2009, -2.6\%, insured full-time equivalents (FTEs), 2008-2009, -2.6\%). In this 12-month time period, the incidence of all work-related disorders declined by $15.9 \%$ in the emergency department records and by $15.6 \%$ in lost-time claim records, and the incidence of work-related MSDs declined by $15.8 \%$ in emergency department records and by $14.7 \%$ in lost-time claim records.

\section{DISCUSSION}

This study has used three independent population-based data sources to describe trends in the incidence of work-related MSDs over an 8-year period in the province of Ontario. These disorders are the leading cause of disability among workers in the developed economies. Over the 8-year observation period, we observed incidence rate declines of $16.3 \%$ in emergency department treatment records, $48.2 \%$ in lost-time compensation claims and $40.7 \%$ among respondents to national health interview surveys.

In the economic recession following the global financial crisis in 2008, the decline in the incidence of work-related injury and illness in the recession was much greater than the decline in the hours of work. ${ }^{28}$ Between 2008 and 2009, the incidence of emergency department visits for the treatment of work-related disorders declined by $15.9 \%$ and the incidence of lost-time compensation claims declined by $15.6 \%$. There are a number of plausible explanations for the observation that the incidence of work-related morbidity declines per hour worked in recessionary periods. During recessions, layoffs and reduced hiring lead to fewer inexperienced workers in employment, less productive (and typically less safe) equipment will be idled and generally the pace of work is slower, reducing the risk of work-related morbidity. ${ }^{28}$ There is also the possibility that workers have greater motivation to defer or suppress the reporting of a work-

Table 3 Annual incidence of self-reported work-related conditions, 2001-2010 occupationally active adults aged 15-64 responding to the Canadian Community Health Survey, Ontario*

\begin{tabular}{|c|c|c|c|c|c|c|}
\hline & $\begin{array}{l}\text { Survey } \\
\text { respondents }\end{array}$ & $\begin{array}{l}\text { Employed } \\
\text { personst }\end{array}$ & $\begin{array}{l}\text { Work-related repetitive strain } \\
\text { injury } \\
\text { Rate per } 100 \text { employed } \\
\text { persons }(95 \% \mathrm{Cl})\end{array}$ & $\begin{array}{l}\text { Other work-related injury } \\
\text { Rate per } 100 \text { employed } \\
\text { persons }(95 \% \mathrm{Cl})\end{array}$ & $\begin{array}{l}\text { All work-related } \\
\text { conditions } \\
\text { Rate per } 100 \\
\text { employed persons }\end{array}$ & $\begin{array}{l}\text { Rate ratio: } \\
\text { repetitive strain } \\
\text { to total }\end{array}$ \\
\hline 2001 & 23485 & 5920000 & $6.81(6.37$ to 7.25$)$ & 2.95 (2.62 to 3.28$)$ & 9.76 & 0.70 \\
\hline 2003 & 25529 & 6185000 & $6.84(6.43$ to 7.25$)$ & 2.02 (1.78 to 2.27$)$ & 8.86 & 0.77 \\
\hline 2005 & 25103 & 6241000 & 6.77 (6.33 to 721$)$ & 2.07 (1.82 to 2.31$)$ & 8.84 & 0.77 \\
\hline 2009 & 12231 & 6321000 & 4.18 (3.66 to 4.69 ) & 1.09 (0.89 to 1.30$)$ & 5.27 & 0.79 \\
\hline 2010 & 12086 & 6408000 & 3.97 (3.33 to 4.60$)$ & 1.62 (1.26 to 1.97$)$ & 5.59 & 0.71 \\
\hline $\begin{array}{l}\text { Predicted rate of } \\
\text { slope }(95 \% \mathrm{Cl}) \ddagger\end{array}$ & & & $-0.36(-0.48$ to -0.24$)$ & $-0.16(-0.23$ to -0.08$)$ & & \\
\hline $\begin{array}{l}\text { Annual per cent } \\
\text { change }(\%)(95 \% \mathrm{Cl})\end{array}$ & & & $-5.3(-7.2$ to -3.5$)$ & $-5.3(-7.8$ to -2.8$)$ & & \\
\hline
\end{tabular}

${ }^{*}$ Canadian Community Health Survey, self-reported work-related conditions that resulted in activity limitation and that received medical attention. Survey weights were used to adjust for probability of selection and non-response. Bootstrap survey weights were used to account for the complexity of the sampling design.

tEstimate for 2001 from Canadian Socio-economic Information Management System (282-0002). Estimates for 2003-2010 from table 1.

$\ddagger$ Parameter estimates of slope and $95 \% \mathrm{Cl}$ from the linear regression model. 
related injury or illness due to concerns about employment security.

Two competing explanations may be considered to account for the declines in the incidence of work-related MSDs observed in these three independent surveillance sources. First, it is plausible that adverse biomechanical work exposures have declined in the Ontario labour force. Unfortunately, this hypothesis cannot be tested directly: there is no source of comprehensive surveillance of exposure to adverse workplace biomechanical demands over this time period for workers in Canada. There is some evidence that regulatory standards can improve workplace efforts to identify and control these exposures. ${ }^{10}$ However, three crosssectional surveys of workers in the European Union between 2000 and 2010 have not detected reductions in self-reported exposures to adverse biomechanical demands. ${ }^{16}$

Alternate explanations focus on the possibility that the apparent reduction in the burden of work-related MSDs is an artefact of changes in the integrity or continuity of measurement. For example, it is possible that the actual incidence of work-related MSDs has not changed over the 8-year observation period. Instead, workers may have substituted other primary care options in the treatment of MSDs over time, resulting in a declining use of emergency department services. Alternatively, deterioration in the diagnostic recognition and clinical attribution of non-traumatic MSD conditions in emergency department settings would result in an apparent incidence decline. In the case of the workers' compensation claims for wage-replacement benefits, it is possible that changes in work accommodation practices have resulted in a decline in the reporting of work disability arising from non-traumatic MSDs. Finally, in the case of survey respondents participating in the repeated cross-sectional health interview surveys, it is possible that there have been changes over time in the perceptions of workers concerning the causal attribution of persistent MSD pain. While there are varying degrees of plausibility for these alternate explanations, it may be less plausible that each of the three surveillance sources experienced a parallel deterioration in measurement continuity.

This study has a number of strengths, including the observation of incidence trends for a complete labour force of six million workers in three independent surveillance data sources. The 8-year surveillance period includes periods of economic growth and contraction. We were able to implement a conceptually concordant case definition of work-related MSDs in each of the surveillance data sources. The use of three independent data sources can inform ongoing controversies concerning the reliability of workers' compensation administrative records where concerns have focused on the integrity of workplace reporting of work-related injury and illness and the omission of information on some classes of workers (self-employed and independent contractors) who are excluded from insurance coverage. ${ }^{38-40}$

As noted earlier in this discussion, the study methods cannot exclude the possibility that the observed incidence declines are an artefact of changes in clinical care-seeking preferences, compensation claim reporting practices and workers' perceptions of the role of work exposures in the onset of MSDs.

Among the 10 most important public health contributions to the improvement in population health over the past 100 years are the achievements in reducing hazardous exposures arising from work. ${ }^{41}$ Despite these contributions, work exposures continue to cause a large preventable burden of injury and illness in working-age adults, and MSDs continue to be the leading cause of disability among Canadian adults. The results of this study are consistent with an interpretation that the burden of non- traumatic MSDs attributed to biomechanical exposures at work is declining among working-age adults in Ontario.

Contributors CAM conceived the study and supervised the study design. AC, $\mathrm{SI}$ and JE contributed to the analysis and interpretation of the study data. PS contributed to the interpretation of the study data. All authors contributed to the editorial preparation of this paper.

Funding This work was supported by a grant from the Ontario Workplace Safety \& Insurance Board (Grant \#11004).

Competing interests None.

Ethics approval Research Ethics Board, University of Toronto.

Provenance and peer review Not commissioned; externally peer reviewed.

Open Access This is an Open Access article distributed in accordance with the Creative Commons Attribution Non Commercial (CC BY-NC 4.0) license, which permits others to distribute, remix, adapt, build upon this work non-commercially, and license their derivative works on different terms, provided the original work is properly cited and the use is non-commercial. See: http://creativecommons.org/ licenses/by-nc/4.0/

\section{REFERENCES}

1 US Burden of Disease Collaborators. The state of US health, 1990-2010: burden of diseases, injuries, and risk factors. JAMA 2013;310:591-608.

2 Lambeek LC, van Tulder MW, Swinkels IC, et al. The trend in total cost of back pain in the Netherland in the period 2002 to 2007. Spine 2011;36:1050-8.

3 Kerr MS, Frank JW, Shannon HS, et al; Ontario Universities Back Pain Study Group. Biomechanical and psychosocial risk factors for low back pain at work. Am J Public Health 2001;91:1069-75.

4 Griffith LE, Shannon HS, Wells RP, et al. Individual participant data meta-analysis of mechanical workplace risk factors and low back pain. Am J Public Health 2012;102:309-18.

5 da Costa BR, Vieira ER. Risk factors for work-related musculoskeletal disorders: systematic review of recent longitudinal studies. Am J Ind Med 2010;53:285-323.

6 van Rijn RM, Huisstede BMA, Koes MW, et al. Associations between work-related factors and specific disorders of the shoulder-a systematic review of the literature. Scand J Work Environ Health 2010;36:189-201.

7 Hauke A, Flintrop J, Brun E, et al. The impact of work-related psychosocial stressors on the onset of musculoskeletal disorders in specific body regions: a review and meta-analysis of 54 longitudinal studies. Work Stress 2011;25:243-56.

8 Mayer J, Kraus T, Ochsmann E. Longitudinal evidence for the association between work-related physical exposures and neck and/or shoulder complaints: a systematic review. Int Arch Occup Environ Health 2012;85:587-603.

9 Coenen P, Kingma I, Boot CR, et al. Cumulative mechanical low-back load at work is a determinant of low-back pain. Occup Environ Med 2014;71:332-7.

10 Foley M, Silverstein B, Polissar N, et al. Impact of implementing the Washington State ergonomics rule on employer reported risk factors and hazard reduction activity. Am J Ind Med 2009;52:1-16.

11 WorkSafeBC. Preventing musculoskeletal injury (MSI): a guide for employers and joint committees. 2001. Vancouver. ISSN 1499-237X.

12 Tullar JM, Brewer S, Amick BC, et al. Occupational safety and health interventions to reduce musculoskeletal symptoms in the health care sector. J Occup Rehabil 2010;20:199-219.

13 Kennedy CA, Amick BC, Dennerlein JT, et al. Systematic review of the role of occupational health and safety interventions in the prevention of upper extremity musculoskeletal symptoms, signs, disorders, injuries, claims and lost time. J Occup Rehabil 2010;20:127-62.

14 Verbeek JH, Martimo KP, Karppinen J, et al. Manual material handling advice and assistive devices for preventing and treating back pain in workers. Cochrane Database Syst Rev 2011;(6):CD005958.

15 Tak S, Calvert GM. The estimated national burden of physical ergonomic hazards among US workers. Am J Ind Med 2011;54:395-404.

16 Parent-Thirion A, Vermeylen G, van Houten G, et al. Eurofound. Fifth European Working Conditions Survey. Luxembourg: Publications Office of the European Union, 2012.

17 Bhattacharya A. Costs of occupational musculoskeletal disorders (MSDs) in the United States. Int J Ind Ergon 2014;44:448-54.

18 Silverstein B, Adams D. Work-related musculoskeletal disorders of the neck, back and upper extremity in Washington State, 1997-2005. Technical Report 40-11-2007. Washington: State Department of Labour and Industries, 2007.

19 Morse T, Dillon C, Kenta-Bibi E, et al. Trends in work-related musculoskeletal disorder reports by year, type, and industrial sector: a capture-recapture analysis. Am J Ind Med 2005:48:40-9.

20 McCoy AJ, Kucera KL, Schoenfisch AL, et al. Twenty years of work-related injury and illness among carpenters in Washington State. Am J Ind Med 2013;56:381-8. 
21 Steenstra IA, Verbeek JH, Prinsze FJ, et al. Changes in the incidence of occupational disability as a result of back and neck pain in the Netherlands. BMC Public Health 2006;6:190.

22 Bureau of Labour Statistics. Chart 21. 2009 Nonfatal Occupational Injuries and Illnesses: Private Industry, State Government, and Local Government, 9 November 2010. http://www.bls.gov/iif/oshwc/osh/case/osch0043.pdf

23 Safe Work Australia. Table 14. Compendium of Workers' Compensation Statistics 2010-2011. March 2013. http://www.safeworkaustralia.gov.au/sites/SWA/about/ Publications/Documents/766/Compendium\%202010-11.pdf

242012 Workplace Safety Index. Liberty mutual research institute for safety. Hopkinton, MA.

25 Linaker $C$, Harris EC, Cooper $C$, et al. The burden of sickness absence from musculoskeletal causes in Great Britain. Occup Med 2011;61:458-64.

26 Davies R, Lloyd-Williams H, Wadsworth E. Analysis of the correlated of self-reported work related illness in the Labour Force Survey. Research Report RR953. UK: Health \& Safety Executive, 2013.

27 Carder M, McNamee R, Turner S, et al. Time trends in the incidence of work-related mental ill-health and musculoskeletal disorders in the UK. Occup Environ Med 2013;70:317-24.

28 Mustard CA, Petch J. The Canadian recession and the compensation of work-related injury and illness. Issue Briefing. Institute for Work \& Health. February 2012. http:/l www.iwh.on.ca/briefings/workers-compensation-claims-and-the-recession

29 Canadian Institute for Health Information, National Ambulatory Care Reporting System Manual, 2008-2009 (Ottawa, CIHI, 2008).

30 Mustard CA, Chambers A, McLeod C, et al. Comparison of data sources for the surveillance of work injury. Occup Environ Med 2012;69:317-24.
31 Canadian Institute for Health Information. The Canadian enhancement of ICD-10. Ottawa, Canada. 2001.

32 Canadian Standards Association. Z-795-96 coding of work injury or disease information. Etobicoke, ON, 1996.

33 Statistics Canada. Canadian Community Health Survey: User Guide for the Public Use Microdata File, Ministry of Industry, Ottawa, Ontario, 82M0013GPE. 2003. http://www23.statcan.gc.ca:81/imdb-bmdi/pub/document/3226_D7_T9_V2-eng.pdf

34 Tyson J. Using a common set of WSIB claim codes to define WMSDs. Unpublished report. 2004. Toronto, ON.

35 Occupational Health and Safety Council of Ontario. MSD Prevention Series. Part1: MSD Prevention Guideline for Ontario. 2007. http://www.iwh.on.ca/msd-tool-kit

36 Morassaei S, Breslin CF, Ibrahim S, et al. Geographic variation in work injuries: a multilevel analysis of individual-level data and area-level factors within Canada. Ann Epidemiol 2013;23:260-6.

37 Smith PM, Mustard CA, Payne J. Methods for estimating the labour force insured by the Ontario Workplace Safety and Insurance Board: 1990-2000. Chronic Dis Can 2004;25:127-37.

38 Boden LI, Ozonoff AL. Capture-recapture estimates of nonfatal workplace injuries and illnesses. Ann Epidemiol 2008;18:500-6.

39 Shannon HS, Lowe GS. How many injured workers do not file claims for workers' compensation benefits. Am J Ind Med 2002;42:467-73.

40 Rosenman KD, Kalush A, Reilly MJ, et al. How much work-related injury and illness is missed by the current national injury surveillance system. J Occup Environ Med 2006;48:357-65.

41 Centers for Disease Control and Prevention (CDC). Ten great public health achievements —United States, 1900-1999. MMWR Morb Mortal Wkly Rep 1999;48:241-3. 